УДК 821.161 .1

\title{
С.В. Морозов
}

\section{НЕКОТОРЫЕ ТИПЫ КУЛЬТУРНОГО ГЕРОЯ В РОМАНЕ Б. ПАСТЕРНАКА «ДОКТОР ЖИВАГО»}

Охарактеризовано значение образа метели в романе Б. Пастернака «Доктор Живаго». Проведен сравнительный анализ отношения Б. Пастернака и А. Блока к революционным событиям 1917 г. и их отражения в «Докторе Живаго» и в поэме «Двенадцать». Исследован образ Юрия Живаго с точки зрения типа культурного героя Подвижника. Дана характеристика образу Антипова-Стрельникова как представителю типа культурного героя - Конкистадора.

Ключевые слова: «Доктор Живаго», культурный герой, культурные ценности, социализм.

DOI: $10.35634 / 2412-9534-2019-29-6-1024-1029$

Художественный мир романа «Доктор Живаго» вписан в особое пространство отечественной философской мысли. Его основу составляют думы и мечты представителей радикальной и творческой интеллигенции, их ощущения и переживания в нелегкий исторический период. Герои романа остро воспринимают разрыв между исторической действительностью и детскими идеалами верности добру и искренности, составляющими лучшую часть русской культуры. Мир представляется им погруженным в хаос и перенаселенным пагубными предрассудками изжившей себя эпохи.

Символом этого хаоса в романе выступает снежная буря, которая будит Юру в ночь после похорон его матери: «Она свистела и завывала и всеми способами старалась привлечь Юрино внимание. <.. > Вьюга была одна на свете, ничто с ней не соперничало» [6. Т. 4. С. 7]. В описании ее появления присутствуют религиозно-мистические мотивы: «Темная келья была сверхъестественно озарена белым порхающим светом» [6. Т. 4. С. 7]. Примечательно, что «первым движением Юры» было «желание одеться и бежать на улицу, чтобы что-то предпринять» [6. Т. 4. С. 7]. Безотчетное стремление героя действовать наперекор стихии вписывается в общелитературный сюжет противостояния светлых и темных сил. Монастырская келья служит маркером условной ситуации духовного подвижничества, традиционно формирующего вектор агиографической литературы. Не случайно Г. Гачев и И.В. Романова применяют к роману среди прочих такую жанровую номинацию как «житие» [5; 8]. В этом контексте с особой иронией воспринимается определение из пасквиля на присуждение писателю Нобелевской премии, опубликованного в «Литературной газете» в 1958 г.: «Книга Пастернака житие злобного обывателя, врага революции» [7. С. 2].

Исследователи не раз усматривали в образе метели в романе мотив, характерный для русской литературы еще с произведений Пушкина, подчеркивали ее роль как воплощения некоего хтонического начала, вносящего разлад в мирное существование героев [9]. Страшная, «блоковская» метель из «Двенадцати» застает доктора уже взрослым в феврале 1917 г., в Москве, в ночь революционного переворота. Переклички между обоими произведениями очевидны, и о них уже тоже писали. От себя добавим к сравнению лишь такую деталь: «На одном из перекрестков (курсив мой. - C.M.) <...> его обогнал пробегавший мимо мальчишка-газетчик с большой кипой свежеотпечатанных оттисков под мышкой.

- Не надо сдачи, - сказал доктор» [6. Т. 4. С. 192].

Реплика доктора неестественно звучит в контексте его жизни в революционной Москве, когда он и его семья бедствовали и должны были беречь каждую копейку. Автор тонко обыгрывает принадлежность Живаго к аристократическому слою общества, как сказали бы в советские времена - к буржуазно-социальному элементу. Живаго пытается читать газету на морозе под фонарем. Свет на газету падает сверху, к тому же на улице холодно, поэтому логично, что доктор должен скорее всего наклонить голову, как бы спрятать нос в ворот верхней одежды. При этом подчеркивается: «Метель хлестала в глаза доктору и покрывала печатные строчки газеты серой и шуршащей снежной крупою» [6. Т. 4. С. 192]. Параллель становится очевидной в сопоставлении со строчками из «Двенадцати»:

Ветер хлесткий! (здесь и далее в цитате курсив мой. - C.M.)

Не отстает и мороз!

И буржуй на перекрестке

В воротник упрятал нос [3. С. 7]. 
Некоторые типы культурного героя в романе Б. Пастернака «Доктор Живаго»

1025 СЕРИЯ ИСТОРИЯ И ФИЛОЛОГИЯ

2019. Т. 29, вып. 6

Блоковский «буржуй» принадлежит к старому миру, и ему отказано в праве создавать новый. Ирония Пастернака состоит в том, что его версия «буржуя» имеет самое отдаленное отношение к паразитирующим слоям общества. Герои Пастернака рыцарски гордятся своими лишениями, более того, их деятельность обладает высокой социальной значимостью. Зять Живаго, профессор Громеко видный агроном. Сам же доктор остается среди тех немногих, кто не покидает службу в больнице, несмотря на ухудшение рабочих условий [6. Т. 4. С. 195]. Юрию Живаго, в отличие от блоковского «буржуя», доверено оправдать высокую культурную состоятельность своей эпохи перед лицом новых поколений. Занимая по отношению к революции наивно-восторженную позицию («Какая великолепная хирургия! Взять и разом артистически вырезать старые вонючие язвы!» [6. Т. 4. С. 193]), называя ее «чудом» и «откровением», герой Пастернака сначала оказывается солидарен с Блоком, который встретил ее не менее оптимистично. Тем не менее вскоре Живаго меняет свою точку зрения на противоположную.

Как известно, автор будущего романа в 1920-е г. пытался принять революцию, создать революционный эпос, не наступив «на горло собственной песне», однако социализм, в который он верил, был еще большей утопией, чем тот, в который верили остальные. Пастернак называл его Социализмом безо всяких кавычек, т.е. не только равным и всеобщим для всех, но и в такой степени претворенным в реальность, что его действие было бы сродни действию нравственного закона внутри человека. Как можно заключить из его письма М. Цветаевой от 23-24 февраля 1926 г., все неудачные попытки своего времени приблизить этот социализм и демагогические выступления по поводу того писатель трактовал как «стилизационные штампы», которые мешают воспринять богатство «непредвосхитимого нравственного содержанья» социализма [6. Т. 7. С. 603]. Здесь же, возможно, прямо полемизируя с Блоком, он заявил: «Наше время $<\ldots>$ не скифская сказка, не точка приложенья красной мифологии» [6. Т. 7. С. 603]. Социализм безо всяких кавычек - это то же самое, что в искусстве понимается как «поверх барьеров» и в силу чего Шекспира и Гёте одинаково воспринимают в качестве «своих» авторов и романтики, и символисты [6. Т. 7. С. 654].

Поэтому в романе Живаго, признавая красоту мыслей Ливерия «об отношении воина народной армии к товарищам, к слабым, к беззащитным, к женщине, к идее чистоты и чести», тем не менее заявляет: «во-первых, идеи общего совершенствования так, как они стали пониматься с октября, меня не воспламеняют. Во-вторых, это все еще далеко от осуществления, а за одни еще толки об этом заплачено такими морями крови, что, пожалуй, цель не оправдывает средства» [6. Т. 4. С. 336].

Предрасположенность масс к лозунгам и демагогии, потеря отдельным индивидом собственного голоса становится самым отрицательным следствием наступившего времени. Безволие общества приводит к социальной катастрофе, к катастрофе культурной, когда накопленный за века духовный опыт грозит исчезнуть в небытии, а его место занимает спущенная сверху Директива. В этой ситуации человек, сохраняющий верность уходящей культуре и сопротивляющийся диктату обстоятельств, подобен герою. Более того, его подвиг, или, вернее сказать, подвижничество (потому что подвиг это нечто единичное, а подвижничество - это уже жизненный путь) имеет огромное культурное и просветительское значение для нескольких поколений людей.

В мировом эпосе и литературе эта роль закреплена за определенным персонажем - культурным героем. Некоторые его черты прослеживаются в образе Юрия Живаго. Например, С.С. Березовская, выделяя тип культурного героя «герой-подвижник», называет его универсальной характеристикой «тягу к путешествиям» [1. С. 69]. Он практически всегда изображается в пути. Юра Живаго с детства оказывается подвержен скитаниям. До смерти матери «...в беспорядке и среди постоянных загадок прошла детская жизнь Юры, часто на руках у чужих, которые все время менялись» [6. Т. 4. С. 8]. Перед тем, как оказаться в доме у Громеко, Юра сначала находится на попечении у дяди, сопровождая его в разъездах, а затем - у дальнего родственника. Жизнь Живаго у Громеко изображается скупо, несколькими мазками, а те эпизоды, в которых непосредственно изображается герой, преимущественно происходят в чужих домах или в дороге. Детское желание «прокатиться <...> ночью по морозу» [6. Т. 4. С. 58] приводит героя к Гишарам, где Юра впервые встречает Лару. Вторая встреча с ней также происходит после поездки по морозной Москве, в ходе которой его посещают важные мысли о Блоке как явлении Рождества, а также заветные строчки «Свеча горела на столе. Свеча горела...» [6. Т. 4. С. 82].

Спокойный ход жизни героя в Москве нарушает война. Примечательна характеристика, которую дает его отсутствию дома дворник Маркел: «...покамест ты там богатырствовал (курсив мой. C.M.)..» [6. Т. 4. С. 167]. Интересно, что исследовательница приводит в качестве примера героя- 
подвижника Илью Муромца [1. С. 69]. Прожив три года в Москве, герои снимаются в путь. Недолго пробыв в Варыкино, Живаго на три года попадает в плен к партизанам. Перед прощанием с Ларой он разговаривает с Комаровским, который говорит ему: «Вы мужчина, вы - вольный казак или как это там называется. Сумасбродствовать, играть своею жизнью ваше священное право» [6. Т. 4. С. 418].

Образ всадника, искателя приключений, иронически навязанный Живаго персонажами - проводниками житейского, преуспевательского взгляда на жизнь, получает неожиданное разрешение в стихах героя, а именно в «Сказке», где идет речь о «конном», спасающем от «змея» «пленницукрасу». А.С. Власов восстанавливает сюжетную предысторию этого стихотворения и связывает его возникновение с волками, которые окружают дом героев в Варыкино, проводя неожиданную параллель с образом Георгия Победоносца: «Георгий в славянских поверьях - еще и повелитель волков, защищающий от них людей и домашних животных» [4. С. 273]. Исследователь также отмечает, что в созданном здесь Живаго лирическом образе «отражаются подлинная, богатая событиями духовная биография пастернаковского героя-протагониста, осознавшего свое предназначение и противостоящего року» [4. С. 273].

Рок, судьба - ключевые понятия в биографии героя-подвижника. Неизбежность является главным и, по существу, единственным его настоящим противником: «зная о возможности "полной гибели всерьез” (курсив мой - С.М), он не пытается избежать того, что “написано на роду”, но стремится стяжать посмертную славу» [1. С. 70]. Показательно, что исследовательница в данном случае иллюстрирует свою мысль строчкой из стихотворения Пастернака 1932 г. «О, знал бы я, что так бывает...» [6. Т. 2. С. 80], которое образно и тематически перекликается с «Гамлетом», открывающим тетрадь Юрия Живаго: «Но продуман распорядок действий, И неотвратим конец пути» [6. Т. 4. С. 515]. Лирический герой «Гефсиманского сада», завершающего тетрадь стихотворений героя, также заявляет о готовности принять свою тяжкую ношу: «Ты видишь, ход веков подобен притче И может загореться на ходу. Во имя страшного ее величья Я в добровольных муках в гроб сойду» [6. Т. 4. С. 548].

Подвижник представляет собой одну из стадий развития Культурного героя. Он имеет прежде всего концептуальное, идейное значение, характеризует развитие понятия культурного героя как универсалии, находящейся в фокусе пересечения искусствоведения, филологии и культурологии, и является мостиком от Трикстера к Сверхчеловеку - от мифологического образа к некой «бихевиористской метафоре» [1. С. 68]. Однако С.С. Березовская рассматривает культурного героя и с другой точки зрения - как маркер того или иного типа развития умственной жизни социума. Если Трикстер в этой парадигме формируется на основе опытного мышления, оперирующего эмпирическими фактами, то другой тип - Конкистадор - принадлежит к теоретизирующему сознанию. В образе Конкистадора получило развитие представление о руководящей роли Разума в жизни людей. Это антипод хаоса и бескультурья в умах людей. Если благая функция Трикстера осуществляется в результате случайности или проделки, то в основе действий Конкистадора лежит четкая мотивация, установка «подарить людям жизнь на лучших началах» [2. С. 77].

Тем же мотивам подчинена жизнь другого персонажа «Доктора Живаго» - АнтиповаСтрельникова: «Стрельников с малых лет стремился к самому высокому и светлому. Он считал жизнь огромным ристалищем, на котором, честно соблюдая правила, люди состязаются в достижении совершенства» [6. Т. 4. С. 251]. Как считает исследовательница, в случае Конкистадора «отправной точкой, своеобразным поводом для приключения становится абстрактная цель, которую рыцарь намечает для себя, а именно отыскать то, чего найти нельзя, или одолеть того, кого одолеть трудно (невозможно)» [2. С. 79]. Так и Стрельникову «не пришло в голову, что он не прав, упрощая миропорядок. $<\ldots>$ он стал лелеять мысль стать когда-нибудь судьей между жизнью и коверкающими ее темными началами, выйти на ее защиту и отомстить за нее» [6. Т. 4. С. 251]. Подобная абстрактность, неразборчивость в целях наблюдается и в действиях Конного из стихотворения «Сказка». В начале стихотворения он «спешил на сечу» [6. Т. 4. С. 528], что совсем не помешало ему свернуть с пути и ринуться на совершение подвига.

Антипов-Стрельников интеллектуально одарен: «Сын простого стрелочника или железнодорожного сторожа, он одною своей одаренностью и упорством труда достиг < ..> вершин современного университетского знания по двум специальностям, математической и гуманитарной» [6. Т. 4. С. 399]. Как отмечает исследовательница, «в Новое время Конкистадор заметно преуспевает на интеллектуальном поприще. Он начинает с самопознания, а затем обращается к постижению природы и социума» [2. С. 80]. При этом результаты его интеллектуальной деятельности «закрепляются в социально- 
Некоторые типы культурного героя в романе Б. Пастернака «Доктор Живаго»

1027 СЕРИЯ ИСТОРИЯ И ФИЛОЛОГИЯ

2019. Т. 29, вып. 6

утопических проектах, направленных на государственное переустройство или усовершенствование политического режима» [2. С. 80]. Социальную утопию претворяет в жизнь и Стрельников, отдавая не только собственное время, но и свою биографию делу Революции. Однако мотивы, которыми он руководствуется, носят не только общественный, но и личный характер. Проявляя нечеловеческую силу воли, он продолжает скучать по оставленной им семье и мечтает вернуться в нее, как только завершит начатое: «А вдруг жена и дочь до сих пор там? Вот бы к ним! Сейчас, сию минуту! Да, но разве это мыслимо? Это ведь из совсем другой жизни. Надо сначала кончить эту, новую, прежде чем вернуться к той, прерванной» [6. Т. 4. С. 252]. Это же понимает и Лара, говоря: «Ему надо все эти военные лавры к нашим ногам положить, чтобы не с пустыми руками вернуться, а во всей славе, победителем! Обессмертить, ослепить нас! Как ребенок!» [6. Т. 4. С. 301]. В образе Конкистадора наблюдаются те же черты, вследствие чего он «каждый раз, как бы далеко ни уходил <..> триумфально возвращается к родным пенатам, к своей Прекрасной Даме, правда, собравшись с силами, рыцарь оставляет семейный очаг $<\ldots>$ ради очередной авантюры» [2. С. 79].

Антипов-Стрельников в романе описывается как уверенный, волевой человек, четко осознающий свою правоту. Это персонаж деятельного типа, решения которого рассчитаны на большой исторический резонанс. В соответствии с этим он и строит свою деятельность в качестве революционного комиссара, когда насаждает искусственный Рай на земле, эффективно проводя в жизнь политику «великолепной хирургии». Осознавая это, он высмеивает внешнюю непричастность Живаго к настоящим событиям, нежелание доктора участвовать в них: «Сейчас Страшный суд на земле, милостивый государь, существа из Апокалипсиса с мечами и крылатые звери, а не вполне сочувствующие и лояльные доктора» [6. Т. 4. С. 251]. Деятельностный пафос в итоге заводит Антипова-Стрельникова в тупик: лучшая жизнь, которую он творил, оказывается для него лишена смысла, более того, он сам оказывается ей не нужен.

Таким образом, стройность теории и торжество разума, которые отстаивает Конкистадор, в «Докторе Живаго» оказываются не главными критериями культурного развития общества. Их значение безусловно важно, но эффективность они имеют только при условии свободного индивидуального выбора каждого. Человек должен постигнуть определенную логику, а не слепо проводить ее в жизнь, не считаясь с законами естественности и простоты. В искренности и неподдельности Пастернак видел подлинные свидетельства непорочности эстетического восприятия, а значит лиричности и силы производимого Художником, Личностью действия. Так, в письме Е.А. Благининой от 16 декабря 1957 года писатель, имея в виду «Доктора Живаго», выражает радость, «что по слепой игре судьбы мне посчастливилось высказаться полностью, и то самое, чем мы так привыкли жертвовать и что есть самое лучшее в нас, художник, оказался в моем случае незатертым и нерастоптанным» [6. Т. 10. С. 289]. А.В. Шевякова напрямую связывает «отказ человека от собственной воли» и «отказ от свободы эстетического восприятия», в результате которых «культура в условиях массового сознания становится заложницей форматов» [15. С. 36]. По мысли исследовательницы, «культурный герой оказывается довольно активным участником творения социальной реальности, так как продуцируемые через культурного героя ценности могут оказывать серьезное мобилизационное воздействие на массы» [15. С. 33]. Л. Флейшман приписывает аналогичный эффект Пастернаку: «творчество Пастернака в целом и в особенности его роман, обстоятельства его создания и завоевания им пути к читателю стали ферментом развития общественного самосознания» [14. С. 60].

Культурный герой Пастернака исполняет свое предназначение в ситуации вынужденного существования в действительности, потерявшей культурные ориентиры. В характерной ситуации «Промежутка» он остается верен не столько лучшим идеалам уходящей эпохи, сколько идеалам вневременным и в силу этого по-настоящему революционным на любом этапе исторического развития. Отечественные писатели, поэты, философы XIX - начала XX вв. в своем творчестве затронули множество различных вопросов, но объединяющим для всех них было представление о высоте и силе человеческого духа, его эстетическом потенциале в отношении действительности и глубине постижения жизни. Пастернак, как и многие другие его современники, формировался под воздействием этих идей. Революция и последовавшие за ней события оказались созвучны им только по величине притязаний, но вовсе не по соразмерности желаемого и действительного. В этом и состояла культурная трагедия новой, советской эпохи. Не случайно А.Ф. Лосев, узнав о смерти Пастернака, заплакал со словами о том, что нельзя и представить «какая погибла Россия, какая погибла эпоха, какая была тогда жизнь, какой она должна была бы стать, какие погибли люди» [13]. 


\section{СПИСОК ЛИТЕРАТУРЫ}

1. Березовская С.С. Концепт Культурного героя как универсалия культуры // Вестн. Том. гос. ун-та. 2010. № 338. C. $68-71$.

2. Березовская С.С. Культурный герой: динамика развития // Вестн. Том. гос. ун-та. 2014. № 387. С. 75-83.

3. Блок А.А. Полное собрание сочинений в 20-ти т. Т. 5. М.: Наука, 1999.

4. Власов А.С. «Предвестие свободы» (О стихотворении Б. Пастернака «Сказка» в контексте романа «Доктор Живаго») // Духовно-нравственные основы русской литературы: Сб. науч. статей. Кострома: КГУ им. Н.А. Некрасова, 2009. С. 270-275.

5. «Доктор Живаго» вчера и сегодня. «Круглый стол» «Литературной газеты» // С разных точек зрения: «Доктор Живаго» Б. Пастернака / сост. Л.В. Бахнов, Л.Б. Воронин. М.: Советский писатель, 1990. С. 265-283.

6. Пастернак Б.Л. Полн. собр. соч. М.: Слово/Slovo, 2003-2005.

7. Провокационная вылазка международной реакции // Литературная газета. 1958. 25 октября.

8. Романова И.В. Семантическая структура «Стихотворений Юрия Живаго» в контексте романа и лирики Б. Пастернака: дис. ... канд. филол. наук. Смоленск, СГПИ, 1997. 275 с.

9. Скороспелова Е.Б., Чаглыян Ш.К. Семантика и функции мотива метели в романе Б. Пастернака «Доктор Живаго» // Филологические науки. Вопросы теории и практики. 2016. № 4-2 (58). С. 41-44.

10. Тахо-Годи Е.А. «И образ мира, в слове явленный...» («слово» в романе Б.Л. Пастернака «Доктор Живаго») / Портал «Слово» [Электронный ресурc]. URL: https://www.portal-slovo.ru/philology/37199.php?ELEMENT_ $\mathrm{ID}=37199$ [дата обращения 04.08.18]

11. Флейшман Л. Свободная субъективность // Пастернак Б.Л. Полн. собр. соч. Т. 1. М.: Слово/Slovo, 2003. С. 5-60.

12. Шевякова А.В. Культурный герой и трикстер: функциональные и онтологические сходства // Вестник Пермского университета. Философия. Психология. Социология. 2015. № 1 (21). С. 32-42.

Поступила в редакцию 14.11.2019

Морозов Сергей Викторович, выпускник аспирантуры филологического факультета

Московский государственный университет им. М.В. Ломоносова

119991, Россия, г. Москва, ГСП-1, Ленинские горы, МГУ, д. 1, стр. 51, 1-й учебный корпус

E-mail: frosttt_78@mail.ru

\section{S.V. Morozov \\ SOME TYPES OF CULTURAL HERO IN B. PASTERNAK's NOVEL "DOCTOR ZHIVAGO"}

DOI: $10.35634 / 2412-9534-2019-29-6-1024-1029$

The significance of the snowstorm image in B. Pasternak's novel "Doctor Zhivago" is characterized. A comparative analysis of the positions of B. Pasternak and A. Blok in relation to the revolutionary events of 1917 and their reflection in "Doctor Zhivago" and in the poem "Twelve" is carried out. The image of Yuri Zhivago is investigated from the point of view of the type of cultural hero - the Ascetic. The characteristic is given to the image of Antipov - Strelnikov as a representative of the type of cultural hero - Conquistador.

Keywords: "Doctor Zhivago", cultural hero, cultural values, socialism.

\section{REFERENCES}

1. Berezovskaya S.S. Koncept Kul'turnogo geroya kak universaliya kul'tury [The concept of the Cultural Hero as a universal of culture] // Vestn. Tom. gos. un-ta. 2010. № 338. S. 68-71. (In Russian)/

2. Berezovskaya S.S. Kul'turnyj geroj: dinamika razvitiya [Cultural hero: dynamics of development] // Vestn. Tom. gos. un-ta. 2014. № 387. S. 75-83.

3. Blok A.A. Polnoe sobranie sochinenij v 20-ti t. [Complete works in 20 volumes]. T. 5. M.: Nauka, 1999. (In Russian)

4. Vlasov A.S. «Predvestie svobody» (O stihotvorenii B. Pasternaka "Skazka" v kontekste romana "Doktor Zhivago") ["A harbinger of freedom" (On B. Pasternak's poem "Tale" in the context of the novel "Doctor Zhivago")] // Duhovno-nravstvennye osnovy russkoj literatury: Sb. nauch. statej. Kostroma: KGU im. N. A. Nekrasova, 2009. S. 270-275. (In Russian).

5. «Doktor Zhivago» vchera i segodnya. «Kruglyj stol» «Literaturnoj gazety» ["Doctor Zhivago" yesterday and today. "Round table" of "Literary newspaper"] // S raznyh tochek zreniya: «Doktor Zhivago» B. Pasternaka / sost. L.V. Bahnov, L.B. Voronin. M.: Sovetskij pisatel', 1990. S. 265-283. (In Russian).

6. Pasternak B.L. Poln. sobr. soch. [Complete works]. M.: Slovo, 2003-2005. (In Russian). 
7. Provokacionnaya vylazka mezhdunarodnoj reakcii [A provocative sortie of international reaction] // Literaturnaya gazeta. 1958. 25 oktyabrya. (In Russian).

8. Romanova I.V. Semanticheskaya struktura «Stihotvorenij Yuriya Zhivago» v kontekste romana i liriki B. Pasternaka [The semantic structure of "Poems by Yuri Zhivago" in the context of the novel and lyrics of B. Pasternak]: Diss. ... kandidata filologicheskih nauk. Smolensk, SGPI, 1997. 275 s. (In Russian).

9. Skorospelova E.B., Chaglyyan Sh.K. Semantika i funkcii motiva meteli v romane B. Pasternaka «Doktor Zhivago» [Semantics and functions of the blizzard motive in B. Pasternak's novel "Doctor Zhivago"] // Filologicheskie nauki. Voprosy teorii i praktiki. 2016. № 4-2 (58). S. 41-44. (In Russian).

10. Taho-Godi E.A. «I obraz mira, v slove yavlennyj...» («slovo» v romane B.L. Pasternaka «Doktor Zhivago») [“And the image of the world revealed in the word ..." ("word" in the novel by BL Pasternak "Doctor Zhivago")] / Portal «Slovo» [Elektronnyj resurs]. - URL: https://www.portal-slovo.ru/philology/37199.php?ELEMENT_ID=37199 [data obrashcheniya 04.08.18] (In Russian).

11. Flejshman L. Svobodnaya sub"ektivnost' [Free subjectivity] // Pasternak B.L. Poln. sobr. soch. T. 1. M.: Slovo, 2003. S. 5-60. (In Russian).

12. Shevyakova A.V. Kul'turnyj geroj i trikster: funkcional'nye i ontologicheskie skhodstva [Cultural hero and trickster: functional and ontological similarities] // Vestnik Permskogo universiteta. Filosofiya. Psihologiya. Sociologiya. 2015. № 1 (21). S. 32-42. (In Russian).

Received 14.11.2019

Morozov S.V., postgraduate student of Philological Faculty

Lomonosov Moscow State University

Moscow State University, building 51, 1, Leninskie gory, MSU, Moscow, 119991, Russian Federation

E-mail: frosttt 78@mail.ru 